\title{
Language Policiy for the Tendency of the Sound Complex in the Albanian Anthroponymy and Patronymic
}

\author{
Prof. Phd. Nexhip Mërkuri \\ Elira Xhakollari \\ University "Ismail.Qemali" \\ Vlorë \\ Albania
}

\begin{abstract}
The authors reflects on the progress of anthroponymy and patronomy sounds tendency and its applied linguistic policy in the last century and the beginning of the new millennium. The research is carried out in two periods: during and post-communism. The authors have done a long-time research on this topic, which has resulted in an accurate argumentative discourse on pre-linguistic choices of these sonoric complex usages in family discourse. The authors have listed carefully the entry of Illyrian/Albanian names and the tendency of sonoric usages, which were part of language planning process; and everything is argued on the basis of national spirit of the time. The linguistic policy of entering of Illyrian names into family discourse is also seen as a general trend of Renaissance (1730-1912) for the purpose of restoring historic memory to Albanians. After the 1990-s, the beginning of democracy in Albania, nonetheless the publishing of the study on newborn names, the linguistic policy has never been applied for many reasons. For the last two years, 2015-2016, linguistics, students, surveyors, educational secretaries, members of civil status, have listed a number of reasons on the choices of the names of newborns in Albania. The freedom of choice of the sonoric complex, the trend of names, the tendency of names in the western world, emigration, etc., are some of the reasons to justify the choices and the linguistic behavior of sonoric complexes. The study is carried out in several municipalities and it is noticed that sonoric choices are highly influenced by the trends in media. There is an avoidance of inherited muslim, catholic and orthodox names and of those names claimed by linguistic policy of 1970-1990. Such linguistic tendency is argued on national basis by making comparisons on the frequency of uses. Diachronic comparisons of Albanian names found in registers of different years reflect the cultural trends of the parents. Albanian families have been quite generous with the borrowings of names from other cultures. Borrowings, as an integral part of linguistic policy, are result of foreign literature, movies, history and fashion.
\end{abstract}

Keywords: Language Policiy for the Tendency of the Sound Complex in the Albanian Anthroponymy and Patronymic

\section{Introduction}

The sound complex of the anthroponymy and the patronymic have attracted many linguists on making that object of their studies even in small spaces, territorially and culturally limited: in one commune or several communes of a district with lot of villages and cities. Also have drew the attention, the second forms of personal names which are a transitory phenomenon or one of the interesting points where the linguistic meets(mixes up with) the unlinguistic therefore it constitutes one of the furrows of further sociolinguistic research.

Other linguistics has seen this sound complex as an arbitrary connection with the humans they name. While they don't have close connections with the humans they name, they can undergo interferences from the family assembly or language policies over the years which can consciously change and replace them with other names, as happens during periods of conquest. 
The community consequently changes their faith and requires the forced change of old naming. Particularly personal proper nouns are subject to this interference. Another cause of conscious changes is the popular etymology, asking from individuals of a family or further more to know the meaning of the name or of the patronymic because after all these are language words. The author of the compiled vocabulary with people names, advises, to explain these anthroponyms to each one : "Proper nouns, as a rule, are depleted from the expressed meaning of the general noun or the word they come from. You can say they get a neutral meaning or "do not have" a meaning at all, they do not express the notions, but they

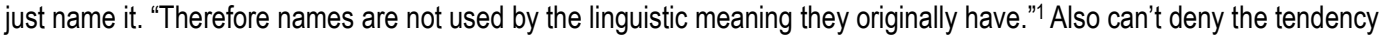
to link their sound form with meaningful words of the language trying to give a sense to words, to their personal proper nouns. In other cases to hide the meaning of personal names from names with bad meanings or pejorative nuance of meaning, the form of patronymic ${ }^{1}$ has been intentionally changed, as will be discussed below by surveys conducted with 100 students, representatives of municipalities: Vlorë, Përmet, Himarë, Selanicë, Berat, Skrapar, Sarandë, Gjirokastër, Këlcyrë, Tepelene, Fier, Patos, Kuçovë, Lushnjë, Divjakë, Durrës, Gramsh, Librazhd, Mat.

Despite the difficulties of the linguist, the family names which are younger should be carefully overcome, though they use the toponym as a subject. The difficulty increases even by other factors, even though their value has to do more not only with the linguistic interest but also with the cultural interest, their bearers, they want to know the origin of their family name. Is already written from other linguistics that the stabilization ${ }^{2}$ process of the personal name, family name has been a long process; going through several stages which extend over a period of time from several centuries, trying to build language policies in these years. Seeking this way, they gathered full linguistic material to complement certain directions and tendencies.

So we researched those regions of incomparable idioms of the North Tosk dialect with the South Tosk dialect or further more. We accomplish what the professor Gj.Shkurtaj has emphasized in several years that this topic will be followed in the future even in surveys and further researches in all Albanian ${ }^{3}$ regions.

More or less is searched the path that has described this fixing and stabilizing process of the sound complex to the personal name, the family name also in the municipalities of Përmet, Këlcyra, Vlora, the municipalities in South and North of the country. Consequences of the linguistic policy in the years before 1990 for the tendency of the sound complex and the sound complex in the democracy years, after the 1990s- till today.

\section{The evolution of anthroponymy and patronymic with the European system of identification.}

When the Albanian principalities were created, the masters were called with patronymic, the family name. Here and there you can face the dominant three-terms formula, the nickname appears as the third element of the formula.

As family name serves also the origin of the place of residence; the patronymics of this type, in the terminology of the field are called patronization of toponyms. Today according to datas they are about $10 \%$ of the family name fund on the municipalities we surveyed and compared, widely treated with in another study.

The features of the formation of sound complex for their denomination and construction are different from one municipality to another. Somehow they vary considering also the regional idiom. The construction of the sound complex composite by joining the surname with the head of the family name, it has a small extension in all the subregions ${ }^{4}$, and in the municipalities we explored.

It is also written by other researchers that the entirety of the Albanian anthroponyms experiences a profound break with the Ottoman occupation of the country. The new Asian conqueror along with the new religion (Islamization) brought with it also the Islamic anthroponymy, which began to prepositioned Arbër's names, that until then were only Christians. However, in Ottoman registers is also reflected at the inherited anthroponymic situation from the pre-Ottoman period; With an anthroponymic of two-term formula, stabilized in centuries later. The Islamization of the population of Albanian cities was

\footnotetext{
1Memushaj,R .Himara's Patronymic in "Himara in Centuries" Tiranë,2004,f.297.

2 Bidollari,Ç. Onomastic research . Tiranë, 2010,f.7.

${ }^{3}$ Shkurtaj,GJ. Onomastic and ethnolinguistic. Tiranë, 2015,f.26.

${ }^{4}$ Zaputi,I. Barleci or Barleti? SF, nr.3 1970,f.170-177.
} 
realized through two paths, first through the transition to Islam of its resident population in cities and the second, through the mechanical movements of the rural population towards the cities.

During the eighteenth century even the population of the provinces of southern Albania was introduced massively to the Islamic path.

The secret Christianity represented a two-dimensional transitional state, through which Christian individuals accepted formally Islam only in order to avoid payment of the Zhizje tax and to enjoy equality with the Islamic population in social life, which began to preposition the Albanians names, whose names until then had been only Christians. However, in Ottoman registers is also reflected the anthroponymic situation inherited from the pre-Ottoman period; with an anthroponymic two-terms formula, stabilized in later centuries. Meanwhile the Islamization of the Albanian cities was realized through two routes, first through the transition to Islam of its population living in cities and second through the mechanical movements of the rural population towards the cities. During the 18th century, the population of the provinces of southern Albania entered the path (road) of mass Islamization ${ }^{1}$

The secret Christianity represented a two-dimensional (religious beliefs) transitional state through which Christian individual accepted Islam formally only in order to avoid payment of the sloping tax and to enjoy equality with the Islamic population in social life. While in public these individuals appeared as Muslims bearing names of the Islamic sphere and went to the mosque in the family they were practicing the Christian rituals.

Among the Islamic sects in question, Bektashism gained considerable popularity and expansion in Albanian territories.

The penetration of Islam in the ranks of the Albanian people may be related to certain features of its ethno-psychological nature, which favors at that time the implementation of the Ottoman Empire's language policy.

Throughout history, the Albanians are remarkable for their pride, seduction and ambition to occupy a social and materially enviable positions in any political and social system. By his nature it has been difficult to accept the disregard, the status of a second-class citizen ${ }^{2}$

However, two significant limitations have been noted that relativize our estimates in this regard: First, the Ottoman land registers, for their own identity do not represent the anthroponyms of the female inhabitants, and second, as far as the male sex inhabitants are concerned, the registrations are limited only by the names of heads of the family and bachelors, only those who paid taxes, so we do not have the full personal name of the whole family in the entire population. This was also the main reason to expand the research for anthroponymy and patronymic. The Catholic contraction is related to the diminishing role of Catholicism in the South of Albania, its gradual withdrawal to the North and to the rural part of the South. This means that it appears generally without endings, the characteristic of non-Albanian orthodox names

So for example: the name or surname "Stamat" is written in the form "Stamad" and not Stamat or Stamatis, as it has been written by linguists over the years. Similarly, we find it written "Niko" and not "Nikos", "Nichola" and not "Nicholas".

Other linguists who have researched anthroponymy and patronymic have underlined the studying difficulty wich extends to the South as well. We also had the experience of the linguist D.Luka at the center of the research: "Often the letters : ç,e,c which are missing in the Arabic alphabet, in the 1467 register are replaced with -xh(j). We doubt as well as for the 1431 register that the guttural $-k$ and palatal $q(k i)$ should not have been pronounced the same, although they are given with the same letter.

While we read the names it's important from the linguistic point of view to differentiate the graphic elements without confusing them with the phonetic ones. For the character itself of the original alphabet it's difficult to distinguish: -s fromsh, -d from - dh,- I from -II and in the 1485 land register also the vowels: i,e,u,dhe $0 . " 3$

The tendency of the sound complex in anthroponymy and patronymic makes it difficult during the research for traditional orthograms, the ability to spell(orthography) names, family names, and the fact of altering alphabets over the centuries.

\footnotetext{
1 Duka, F. Ottoman centuries in Albanian space.Tiranë, 2009,f.47.

2 Duka, F. Ottoman centuries in Albanian space.Tiranë, 2009,f.57.

${ }^{3}$ Luka, D. Language observation on the onomastics of the Ottoman cadastral records of XV century $(1431,1467,1485)$. SF.4, $1983, f .161$.
} 
On the other hand in many cases you can find registered as names also family names, in their abbreviated form, characteristic of orthodox anthroponymy such as for example: Koço or Koc instead of Kosta or Konstandin ${ }^{1}$. Sound complex such as personal names are found in other municipalities of Përmet as well, like: Ninka, Tanuçi(Q), Metushi(Ç), Sulçe(F), Pelushi(P), Agushi(V), Lako(SH), Malushi(Ç). only for the letter (T) we can mention: Tice, Todhe, Todi, Tore, Toska, Toti, Tralo, Tuku, Tundo etc.

Also, there are not uncommon ameliorative forms in the name formation or surnames of the city inhabitants, which are characteristic of the Albanian variant of anthroponymy: Sulçe(F), Pelushi(P), Agushi(V), etc.

Ethnopsychological reasons, the long period of Islamic linguistic politics is accompanied by other changes that represent the youngest older names in most cases, are well explained through the historical phonetics of the Albanian language by making them objects with linguistic value.

In some areas of the northern edges, in researched registers by linguists, prevails Slavic-Orthodox anthroponomy. The emergence of these names with total Albanian clothing can be explained by the lack of analogous forms of Slavic names, thus the inability to adapt to them. Slavic suffixes emerge only on a Slavic root. These are rarely linked to local topics.

Most of the Slavic names with their own correspondent in both the Albanian and Slavic vocabulary(lexicon)are translations from Albanian to Slavic language just for easiness of use by the administration not excluding administrative interventions with certain goals as one of the forms that use sometimes invaders. Here you can add new personal names according to the country's configuration, tree-names or any other distinguishing element according to the French linguist Dauzat, Albert in his major work: " Les noms de famille de France". (Paris,1949, f.180)

A full study has been carried out according to Belgian researcher Eugen Vroonen, who distinguishes within this type of patronymies: names that characterize physical characteristics like: age, hair color and skin, mentioning of an organ or part of the body, various mutilations, wounds; beauty, body ugliness; strength, vitality and weakness, morality characteristics, profane names, religious names, moral strength and weakness, justice, sincerity, self-restraint; arbitrariness, severity, hypocrisy, flattery, lack of language, elegance in clothing, main sin or virtue, miserliness, generosity, hot-temper/peaceful, envy, laziness, carelessness².

It's written that language policies over the years have brought a movement within the system with rapport displacement until the system closes with the establishment of the first administration of the Albanian state and especially with the first population census (in 1923); "registration is repeated every 10 years until 1945. It takes place in these years after the Second World War, until 1 September 1948, when the law on personal names was adopted, which is published in the "General Codification of the Legislation" in force on the Popular Republic of Albania, Annex 1959-1960, Tirana. Prime Minister's Edition, 1961.

This system was improved year after year, according to this variety of types and forms, and it manages to identify the citizens with the two-term formula and in too formal circumstances uses the three-term formula. to make it work more accurately.

However, this system is the result of a long evolution that is in full compliance with the European system of identification.

\section{Language policy of the years before 1970-1990 on the tendency of the sound complex}

Even before the 1970s and onwards, many linguists treated in full articles the names of the population and the names of the families. Complete publications were also made. In those years was also published a vocabulary of about 5000 people names that was published as an appendix in the "Vatra e Kultures" (Culture Hearth) magazine, in 1972, mainly with Albanian source or Albanianised that served as a guide to parents and their employees.

Then this list was elaborated by a group of linguists who worked in the field of anthroponymy and was published as a separate book "Dictionary with people's name", 1982. That period has left a very beautiful footprint in Albanianhood and the common names of people in Albania and almost throughout Albanian lands. ${ }^{3}$ We can not say that it continued to act

\footnotetext{
${ }^{1}$ Same book, f.244.

2 Vrooenen,E. "Les noms de personnes dans le monde"(Antroponymie universelle compare) 1967, f.409-426.

${ }^{3}$ Shkurtaj ,Gj. Onomastic and enolinguistic.Tiranë,20015,f.28.
} 
as a "patriotic trend" in naming proper nouns, but we see it clear at the municipalities that surveyed the voter lists of the two municipalities, which reflected perfectly both genders. On the telephone numbers of the city of Vlora and Përmet, ${ }^{1}$, the literature emphasized in the frequency of using those names, who built for those years the language policy for the people's names

Anthroponyms, sound complex, chosen by family assemblies with local source, that have the greatest use which are reflected in the chart below:

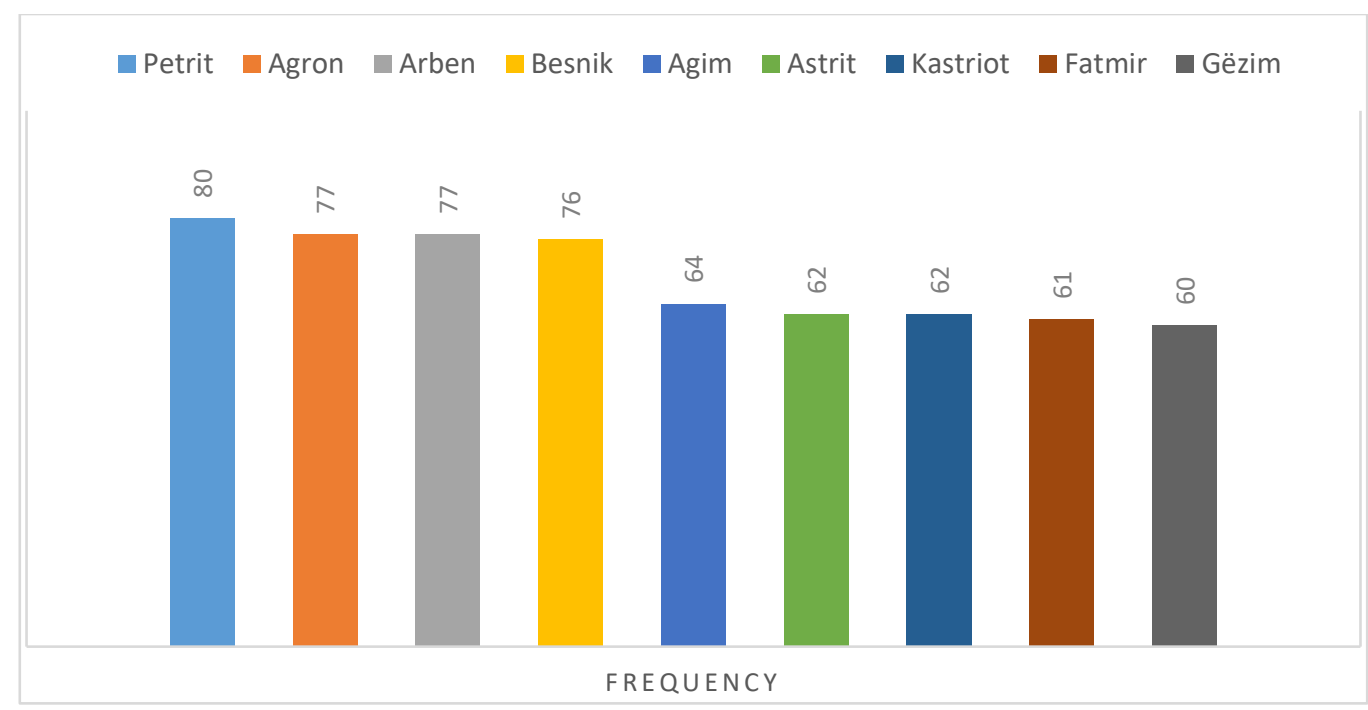

Graphic (chart) nr. 1. Anthroponyms with local source that have the greatest use

Personal name concepts, as a sign, are different. We mentioned above some of the linguistic thoughts. The name sign (stamp) is also viewed in the sociolinguistic aspect. Putting a child's name is an act of will and a social obligation, somehow the child always carries the parents blessing together with the belonging to a culture, a religion, or a happiness vision of tomorrow's world. He's going to keep that name for life, the name that others gave him, as a distinguish sign and at the same time as a sign of union with the surrounding society. The tradition has been the establishment of families assemblies for all, family members are active in discussing and selecting the name. The family assembly decides on the sound complex that the child will hear thousands of times. The man and his name are inseparable, the name lives even after man's dead, to remind his descendants of his work. Somehow the name is not like any other sign. He is a living sign. ${ }^{2}$ The longevity of the individual's name was a concern for the family generations when they reflected the language policy of these years. Grandparents, parents who preside over families assemblies worry about the naming: First, how will it be caressed in the family;

Secondly, how will it sound when is placed next to determinative like: uncle(sire, old man), or auntie, when he reaches a certain age; till to the beautiful sound of ear when this sound complex was associated with over-segmental elements. The language politics of the time also affirmed some of the names of animals, birds, and plants by expanding the meaning of the general noun, reflecting it also in the following graphics.

\footnotetext{
1 The onomastic material we used as a sample for the study: personal names and family names, Based on sources obtained from the 2013 electoral registers of Vlora's city, the list of names from the (ISSH) SSI of the Sevaster and Armen communes and Vlora's telephone numbers of 2003, Përmet's telephone numbers of the year 2003 etc.

2 Kostallari, A. "People and names", National Literary Standard and Language Culture, 1.vol Tiranë, 1973, f. 361.

The names and family names that we have taken for the study belong to individuals over the age of 18, who are reflected in the language policy of the 1970s that we left behind.
} 


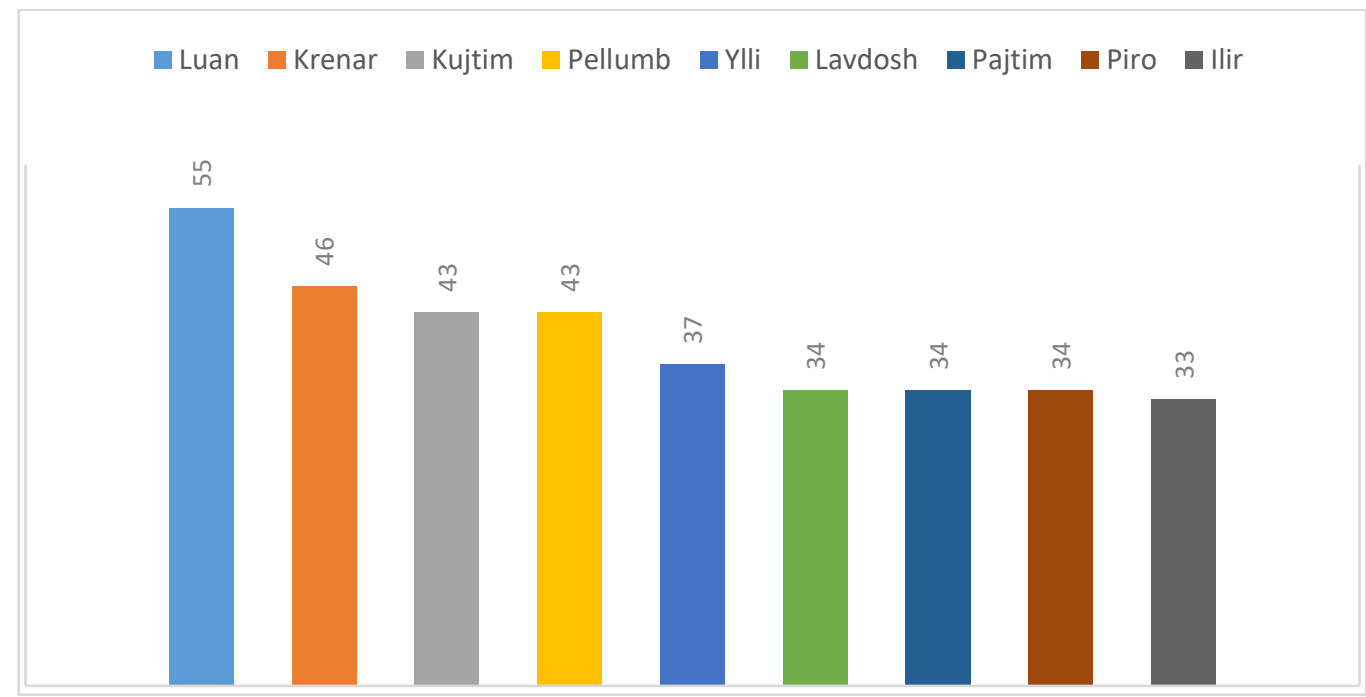

Graphic Nr. 2. Anthroponyms that derive from animals and birds names, and formation with the suffix -im Anthroponyms from local source that have the highest use frequency

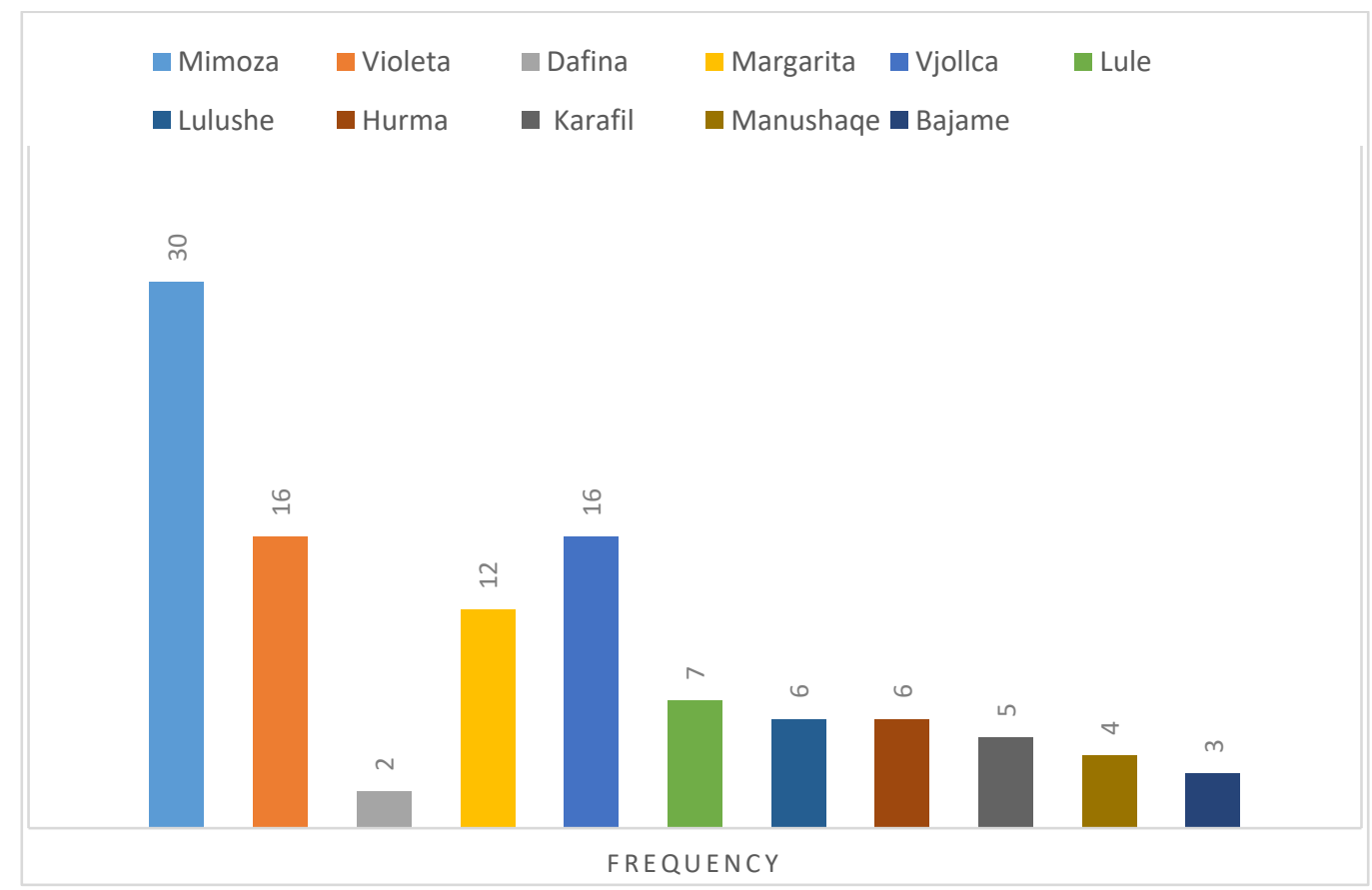

Graphic Nr.3. Anthroponyms derived from plant names 
The observation of time records reflects the Albanians names through the years, you can learn not only the family's religion, or the tastes and cultural tendency of the parents, but more or less the generation they belong to. As well as other times, Albanian culture has shown itself unsparing with loanwords from other cultures that have accessed us through literature, films, history and fashion.

Normally when you prepare to put a child's name, you are always forced to follow different conventions, different signs, complex sounds that sound nice and are distinct as sound waves for the ear, for example: religious or national; which always refer to the total temptation of baptismal authority. There are also limitations in the space that remains relatively out of the sphere in which this authority operates, since many times the child is named after his grandfather(grandmother), or another name, based on a variety of rules that may relate to the family proximity and kinship structures; or with the calendar: or by the order of birth etc.

The parent is free to choose a name beyond religious, nationalist, traditional, ritual, consideration etc; And this choice can not only be aesthetic; so the chosen name should be beautiful. Of course it can not be denied that aesthetics plays a first class role in personal name selection; at least the modern Albanian, can no longer experience the evocative force of the name that was possibly linked to once. The factors listed above about these years and language policies, correctly implemented by Civil Status Offices, family assemblies also mapped out some tendency. Almost mandatory, the tendency of this policy are also reflected in the use frequency on the graphics presented, such as: plant and animal names, abstract names, by mapping out the Albanian culture etc.

\section{The sound complex in the years of democracy, after the $1990 \mathrm{~s}$}

The system change brought also changes in language policy for the tendency of the sound complex to the anthroponymy and patronymy and on. The above mentioned language policy began to be implemented less, even for the main factor that the institution that planned it did not applied the best realization of the distinctive tendency of the sound complex in anthroponymy and patronymic. The propensity of the sound complex with Illyrian names and remarkable figures starting from the beginning of the twentieth century it looks like it fades, to be interrupted. It is not involved in fashion while it brings linguistic culture over the years and puts Illyrian names as part of a general trend of the National Renaissance to restore the historic memory of Albanians. A tendency increase is not noticeable nor for the tradition initially launched among the middle classes of citizens. In other social classes as well there is no tendency to use names that belonged to distinguished men and women of the nation and plant and animal names.

Linguists treated in conferences also special publications for the policy improvement, the consolidation of the best tendencies and the Linguists addressed special conferences and publications to improve policy to consolidate the best trends and distinctions as any other European nation..A survey was conducted with a sample chosen by the country's municipalities in the north and the south. Survey questions aimed at expanding the argument for the family assembly, setting the anthroponymy, patronymic and its choice and aesthetic, which led to the chosen tendency of the sound complex. Family assemblies for all students are active in the family for discussions and selections of the personal name and family name.

Among these choices are those who are influenced from media and literature.

These assemblies continue today in the explored regions for anthroponymies and patronymics.

To the question "How did you get your name?";

$70 \%$ respond from the names of speakers, singers, winners of beauty contests, character actors (main actors):Jonida, Zhuliola, singer's name; movie actor: Sonila, Abigela, Paula, Ornela, Marjeta; book character: Asjola, Osjola, Olta; winners of beauty contests: Sidorela, advertisement's name: Lori, Lorena.

$10 \%$ of the names were set by letter's merging: mir + ban <Mirban, two brothers Er+ $s+j a n<E r s j a n a$, two parents names, grandfather's sisters, aunties names: Sa+ina<Saina, Marianthi, art+ ilda<Arilda etc.

$5 \%$ of the names are set as grandfather's, grandmother's, aunt's(mother's sister), aunt's(father's sister) and other relatives legacy who want to perpetuate their name even when they are alive although, once afflicted, by most parents of rural areas is mostly preferred the traditional by reseting their parents names. To the question "How do you choose aesthetically a 
beautiful name for you and for your family members and your relatives(tribe)?"; According to sub-zones with different concepts even when it is a borrowed name.

Selecting a name by the aesthetic beauty of the sound complex from the family or other members in the family assemblies which are comfortable with what this sound complex means: Ersila ,Ersi - goddess, Sara- princess, Habibe<love, Siderelamusic, passion, Zajmira <good voice, Gëzim-a boy after two girls, Euxhenia - well-born Flutura - to be beautiful as a butterfly, Sotira- good-hearted,, Juliana - is a christian name, feminine beauty name.

$1-2 \%$ take place the islamic inherited names, and it is not supposed to replace this sound complex

$1 \%$ Are expressed for changing the sound complex by stressing out those sounds complex, those names that are most used on the Internet: Sara.Todete> Odeta, Juliana, etc.

The sounds complex chosen as a proper name, which has as its basic function simply the marking, the individualization of the living being, putting a label on each of them, so that the individual or object named is easily identified and distinguished from other individuals. Sound complex recorders assert that parents choose the name aesthetically and ease in pronunciation, usually are chosen names with fewer words: Emi, Ana, Rei, Ina, Ami.

So the above trend it's not noticeable by the fulfilling of the reports presented in the graphics with the names of flowers and animals becomes rare, have a frequency of use up to one as well as those formed with the suffix -im.

Proper nouns, since they do not mark concepts, have no content. Few are the students who ask for the meaning, the etymology of the sound complex, how can they be translated; and consequently changing the name.

The biggest reason for the changes is the adaptation with the name that is fashionable in the country where they emigrate together with their family. To the survey's question

"Can you write any case of changing the name and family name and the reasons?"

They line up as a motive for changing their name at first the trend of emigration: Xhevair < Jani, Ferlando < Andi, Landi< Fabion, lives in Germany, Agron<Sami, Mjaftime< Sidorela, Era<lrini.

The emigration's reason has continued with the choice of the sound complex for the family name as well: Shehaj <Stefani, Shaqiri < Karpuzi, Gjoka < Gjika, Gjoleka < Kristo.

To the question "Has your family name changed?" They answer by listing the reasons for adapting to the sound complex of the family name for emigration reasons like for example: Shehaj<Stefani,Shaqiri< Karpuzi, Gjoka <Gjika, Gjoleka< Kristo, but also changes for property reason like:Cjapi <Sabriu, Dangaj <Kajo, Vaso <Sefraj, Asllanaj <Aliu etj.

It is also claimed by sound system recorders that during the period post-1991 many families, which emigrated, because of the documentation or even insults, especially immigrants in Greece, have changed their names as well as the columns of motherhood and fatherhood reflecting from Muslim names in Christian names: Fatime<Fotini,Vesel<Vasil etc.

To the question "Why someone has two names?";

There are several alternatives: 1-2\% have two names: Bush for Qamil, Zenel for Maxim, Fiqirete for Ornela. The first one now replaces the grandfather who has already been renewed as a name and others for immigration reasons.

They call as second name the family ameliorative done in the family for the family register and the casual register carried out with sound drops in different positions such as: afheres: Oligerta>Gerta, Aligerta>Gerta, Euxhenia>Xhenia, Todeta $>$ Deta, Elfrida $>$ Frida, Elisa $>$ Lisa, Abigela $>$ Gela, Trifon $>$ Foni, Domalda $>$ Alda, Pamela $>$ Mela, Sidorala $>$ Dorela, Kristabela>Bela, Ervina> Vina;

and apocope: Juliana >Juli, Marjeta>Mari, Emirjana>Emi, Enelita>Eni, Jugerta>Jugi

They form this second name for family records and careless in various ways with additions and ameliorative suffixes: Ersjana $>$ Cole, Armada $>$ Didi, Olta $>$ Oltush, Gëzim $>$ Xhimi, Anxhela $>X h e k u>X h e n i$, Asjola $>$ Asi, Paula $>$ Pau, Flutur $>$ Luçi, Arbana>Bai, Bleona> Lona, Zajmira> Zami, Sotira>Tirka, Olta> Oltush etc. 
It is written by the linguists that a part of the inhabitants registered in the daftar(land registers) of 1583, they kept as names as well family names, characteristic of the Albanian ethnicity. A part of the registered residents in 1583 within the "Muslim community" still held a Christian family name of early Islamization period as: Hasan Gjoni etc. Emigration into different countries of Europe has shown the trend in adapting the name and family name of the country where he will be placed to work. While younger generations have come to the "throne" of heritage, selecting names from centuries-old national tradition is a neglected job by the eldest after the 90 s who have not turned it into tribal and family education the setting of Albanian names.

Has fashion influenced into the choice of the sound complex displayed on the web pages?

Are they reflected in the choice and now the setting of children's names?

The selective family assemblies of the child's name sound complex appear to be reflected after the 2000 s, when they were also used by the population: computers, tablets, and cell phones. With these tools they can easily find the promulgated trend by the Social Security Administration, but also the one in the country where they will emigrate.This information is participant in the family assembly, or talking on Skype etc. The most favorite names for children beyond Albania: Jacob and Sophia are the most popular names for infants(babies) born in 2012, as has announced the Social Security Administration. The list was filled with names from the Bible, pop culture, but also with characters names from media: Jacob for eighteen consecutive years is at the top of the list, in terms of names for boys. The most favorite names for men in some generations are: Gilbert, Michael, David, John, James, William, Matthew und Robert. Meanwhile for girls' names preferences change more often. So in the last 5 years, four different names have dominated the preferences for girls' names. From 1996 to 2007, Emily was the most favorite name, but from 2007 and beyond the names Emma, Isabella and Sophia are the most popular. Below are 10 names for men and women who are or are expected to be most preferred in the years to come, and may be anthroponymies tendencies and later patronymies with some little changes in the letter and the entire sound complex even in Albania.

10 the most used names for girl and boys, with are discussed from family assemblies:

\begin{tabular}{|l|l|}
\hline Boys & Girls \\
Jacob, & Sophia \\
Mason & Isabella \\
William & Emma \\
Jayden & Olivia \\
Noah & Ava \\
Michael & Emily \\
Ethan & Abigail \\
Alexander & Madison \\
Aiden & Mia \\
Daniel & Chloe \\
& \\
\hline
\end{tabular}

This fashion was observed in some municipalities of North Tosk dialect and Labëria, Vlora Municipality selecting the sound complex during 2015.

In the Municipality of Përmet and Këlcyra the names of Islamic origin that were once dominant during 2015 are rarely settled, only once, the frequency of use is one: Sinan.

Melodi, Burbuqe that once before the 90 s were preferred or trendy on the family assemblies were repeated only once. In both municipalities is noticed the placement of two syllables names: Roi, Nergis, Matias; Names that are not pronounced with $-\mathrm{s}$ are being written as they were borrowed from the respective languages.

Most of the names are set according to the trend that appears online: Afrosta, Izabela, Mikele, Aluesta, Vanesa, Dario, Juel, Elena, Joel, Noemi, Serxhio, Aria, Flojdi etc. In the municipality of Këlcyra, the sound complex chosen for the year 2015 with the highest frequency is Noel, with two variants Xhoel, Roel (3) Ajla (2) Melina (2) etc.

In the Municipality of Vlora it is settled by family assemblies: Emi,Ana,Rei,Ina,Ami etc. 
In all three municipalities that we have explored, there is a tendency to choose the sound complex from trends shown in the media, so it is a common phenomenon with wide-range. Have been avoided inherited Muslim, Orthodox names and Catholic names, even those tendencies who succeeded in the language politics of the 1970s-1990s. This trend is further argued in the anthroponymy and patronymic to a wider national level. There is anxiety when examining the sound complex chosen by family assemblies wider than the aforementioned municipalities.You can feel the concern when you consider the sound complex chosen by family assemblies wider than the aforementioned municipalities.

So this is confirmed by the latest INSTAT (Institute of Statistics) data, that from more than 35,000 children born in 2014, the most popular name is Amelia, followed by Amelja, Ajla, Melisa, Klea, Sara, Kejsi, Noemi, Alesia and Leandra. The sound complex for male children, at the top is Noel, followed by Joel, Joel, Mateo, Ergi, Luis, Aaron, Samuel, Roan and Roel. But referring to BIRN, none of the 20 most commonly used names for newborn babies in Albania have no Albanian roots or they aren't constructed according to the aforementioned Albanian linguists policies. From the above presentation we clearly see the remark of 70 years ago that $\mathrm{H}$.Boissi formulates in his statement: "There are few family names formed by first names as abstract": "Shkëlqim". It is explainable, why such names have not passed in patronymic, it is surprising to us what comes out in the Cadastre and Concessions Registry for the district of Shkodra in 1416-1417 "pathronymic Kujtimi, Pjetër Kujtimi ${ }^{1}$, which is not encountered neither today in the material collected in the district of Përmet. While in other municipalities the student's paternity for the years under review have a usage frequency of up to $50 \%$ the names that are fashionable: Agim (5), Kujtim (4), Gezim (3) etc.

Though the personal names formed with the suffix -im have a high frequency of use after the language policy of the 1970s: Agimi (64) Kujtim(43)Pajtim (34)Bashkim (31) Shkëlqim(27) etc., are not transferred into family names. Maybe it takes time to turn to family names.

This wide, beautiful tendency is not mentioned by student enumerators, it is avoided by the enumerators, by not mention it. The above changes are also argued with other factors that reflect the survey conducted with students of the first-year for language-literature, with first-year master's degree Language and Literature students in May 2016.

So to argue further the language policy for anthroponymy and patronymic we expanded the geographic extent in many municipalities in the country. We analyzed for two years the names of students coming from the municipality that lie in the north of the country. The anthroponymy and pathronymic of first year students in the Faculty of Human Sciences, at "Ismail Qemali" University, we examined to see what was the most widely used name with the highest frequency for the years 2015-2017. How it went on with the trend choices from the family assemblies even on the threshold of 1998-2000 for the sound complex? How does go on this trend this with the parents anthroponymy and patronymic? How are they reflected in student names by calculating the frequency of use and the comparison with the graphics of the years 19701990 above?(4),Antonela ((4),Sidorela(4)Esmeralda (4)Sara(4),Klea(3),Anisa(3)Xhoana(3), Daniela(3) etc.

Academic Year 2015-2016,2016-2017, First year at the Faculty of Human Sciences

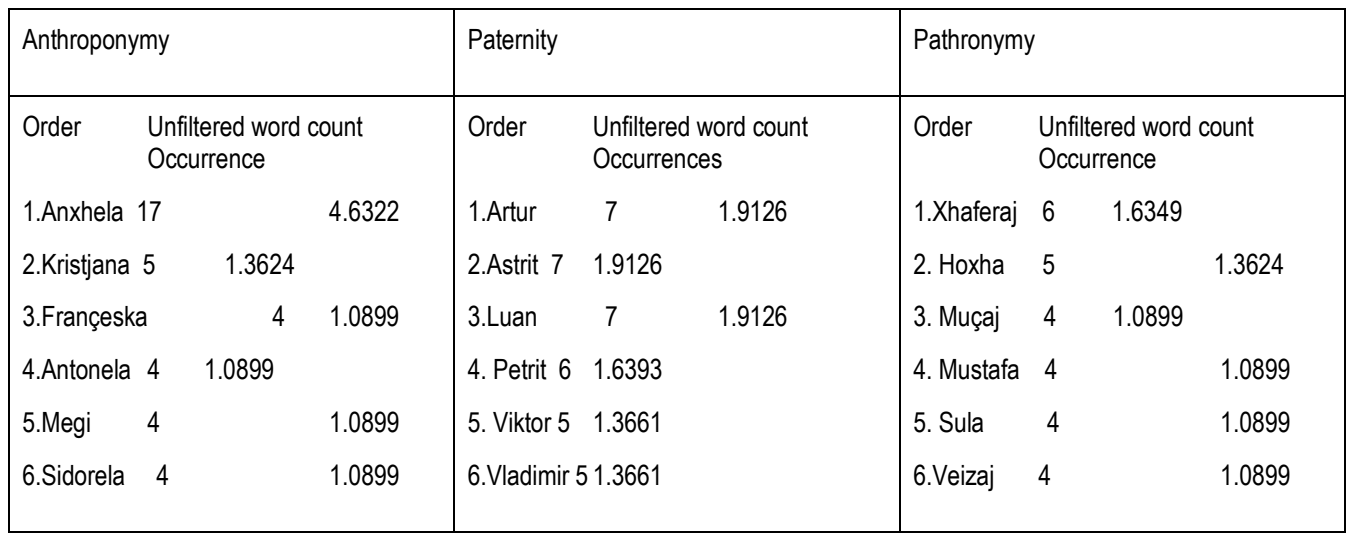

${ }_{1}^{1}$ Bibollari, Ç. Onomastics Research Tiranë,2010, f.57. 


\begin{tabular}{|c|c|c|c|c|c|c|}
\hline 7.Esmeralda & 4 & 1.0899 & 7.Agim 51.3661 & 7. Halili 3 & & 0.8174 \\
\hline 8.Sara & 4 & 1.0899 & 8.Sokrat 41.0929 & 8. Breg & & 0.8174 \\
\hline 9.Ermelinda & 0.8174 & & 9.Arben 41.0929 & 9. Doko & & 0.8174 \\
\hline $10 \mathrm{Klea}$ & 0.8174 & & 10.Ardian 41.0929 & 10.Meta & & 0.8174 \\
\hline 11.Anisa & 0.8174 & & 11.Artan $4 \quad 1.0929$ & 11. Hoxhaj & 0.8174 & \\
\hline
\end{tabular}

The tendency of sound complex for student's parent is quite different from that of the student by having a high usage frequency: Artur (7), Astrit (7), Luan(7), Petrit (6), Vladimir (5), Agim(5) etc.

While patronymics reflect just a little bit from language policy as they change very slowly by coming out with greater frequency of use: Hoxha(5)+ Hoxhaj( 3), Xhaferaj(6), Muçaj(4) etc.

wich are inherited pathronymics for centuries and fossilized by Islamic language policy of five centuries ago.

Language policy before the 1990s brought the addition of names :, Dafina, Agim, Vjollca, Luan, Lumturi, Besnik, Dashamir, Dhurata, Majlinda, Liri, Bekim, for whom there has always been authentic tradition, Illyrian names such as:Agron, Teuta, Ardian, Enkeleida, Bardhyl, Taulant, etc. wich were completely unknown to family assemblies as a whole. This language policy of the lllyrian names introduction can also be seen as part of a general trend of the National Renaissance to restore historic memory to Albanians by making it part of family assemblies by selecting the sound complex.

From the changing of the system, the beginnings of democracy 1990 - today, this language policy with all the editions and studies of names, family names did not apply for many other factors listed by surveyors such as: freedom of choice for the sound complex, the trend of the names comping from the west, emigration's trend etc.

The entire number of baby names born in these years especially those related to the most important parts of the Albanian language community with the lifestyle and the spiritual and material culture of it, are less preserved intact, do not come up as a trend.

Civil Status Employees implement correctly the list of prohibited names (2008). These names are considered to express negative qualities and are commonly expressed in everyday life. This makes them unsuitable for ordinary use, which is not reflected in the names of students, preschool children, and on the birth lists of 2015 in the surveyed municipalities. Parallel can also be applied as well the prudent work of the linguist V. Zoto, "Name's Dictionary. "(2005) and other dictionaries to carefully select the Albanian sound complex from family assemblies. 